\title{
Respiratory function measurements in a cohort of medical students
}

\author{
P. J. LA W THER, A. G. F. BROOK S, a nd R. E. W A L LER \\ MRC Air Pollution Unit, St. Bartholomew's Hospital Medical College, London, E.C.I
}

\begin{abstract}
The feasibility of studying respiratory symptoms and lung function on a cohort basis from adolescence onwards has been examined by a study of a group of 102 medical students on entry to their course. In the present paper the results from the initial examination and from a second, four years later, are reported. Up to that time smoking habits were light, and there was very little change in any of the measurements of lung function. Transfer factor declined a little, and this was the one quantity that showed some relationship with smoking within the present group. The results provide a valuable baseline for subsequent measurements on the same group. If subjects can be persuaded to come for measurements, it would appear to be practicable to conduct larger studies on similar lines.
\end{abstract}

Chronic bronchitis is a disease of long duration and many causes, and comparatively little is known about its mode of onset. Douglas and Waller (1966) have demonstrated the effect of urban air pollution on the prevalence of lower respiratory tract infections in infancy and childhood and have shown the value of prospective surveys in the study of bronchitis. We have now selected a small cohort of medical students for a prospective study to see if certain symptoms or deviations from 'normal' values of lung function have prognostic value. We were interested primarily in the effects of environmental factors such as air pollution and of smoking habits on respiratory symptoms and lung function, and, apart from its accessibility, this group had advantages in that smoking histories were short and many of the members had not previously lived in a large urban area.

Results from a number of 'cross-sectional' studies in which lung function has been examined in relation to sex, age, and height have been assembled by Cotes (1968), and many other studies of this type have been reported or are in progress (Ashford, Brown, Morgan, and Rae, 1968 ; Lowe, Pelmear, Campbell, Hitchens, Khosla, and King, 1968). In some of these it may be possible to follow a proportion of the subjects through their working lives so that the results can also be examined on a cohort basis, but so far there is little information on changes in lung function in cohorts of men and women as they pass through adult life.
Peak expiratory flow and forced expiratory volumes are the parameters most commonly measured in large-scale surveys, because of the simplicity of the methods. However, other aspects of lung function deserve attention. We therefore planned to examine a number of other quantities used in clinical practice (including transfer factor and subdivisions of lung volume), and one of the objects of the present small-scale study was to test the feasibility of making a wide range of lung function measurements in survey work.

The present paper reports the prevalence of respiratory symptoms and the distribution of forced expiratory volume, peak expiratory flow, lung volume and transfer factor measurements at an initial examination on entry to the College, together with the changes observed at a second examination, four years later. 'Survivors' of this group should be traceable through the Medical Register, and if they can be seen again at intervals during their subsequent lives it should be possible to obtain useful information on the development of symptoms and signs of bronchitis even from this small group.

\section{MATERIAL AND METHODS}

The population consisted of the 1962 intake of students to the Medical College of St. Bartholomew's Hospital. Having obtained the permission of the College authorities to conduct the enquiry on a wholly voluntary basis, a letter explaining the objects of the survey was sent to each student in 
January 1963, and those willing to participate were invited to return a slip from the bottom of the letter. The initial response was disappointing, but after repeated efforts (including 'accosting' the students outside lecture theatres!) all but one of the 103 students agreed to co-operate.

The Medical Research Council Short Questionnaire on Respiratory Symptoms, 1960 (Medical Research Council, 1962) was used throughout this study, but additional information was obtained on the father's occupation, history of allergy, residential history, and whether the student was taking an active part in sport and athletics. All the interviewing was done by one person (P. J. L.), and determined efforts were made to complete this part of the study before the end of term (March 1963). The initial interview took about 30 minutes and it included a clinical examination (heart and lungs) and blood pressure measurements.

The students attended on a separate occasion for a series of lung function measurements, taking about one hour to complete. Forced expiratory volume was measured first, using a light-weight spirometer of our own design. We tried to obtain five technically satisfactory tracings from which the forced expiratory volume at three-quarters of a second $\left(F E V_{0.75}\right)$ and at one second $\left(\mathrm{FEV}_{1.0}\right)$ were read, together with the forced vital capacity (FVC). Many of the students proved to have large vital capacities, beyond the volume of the spirometer bell, and we could not obtain a complete set of FVC results. The means of the five readings of $F E V_{1.0}$ were used in subsequent analyses, but in a few cases one or two tracings were excluded. Peak expiratory flow (PEF) was measured using the standard instrument described by Wright and McKerrow (1959). Five readings were obtained with each subject, and analyses were based on the means of all five. The measurements of forced expiratory volume and peak flow were repeated after administration by inhalation of a bronchodilator (isoprenaline). Heights and weights were also measured during this visit: men were measured in shoes, subtracting a standard $2.5 \mathrm{~cm}$ afterwards to allow for this, and women were measured in stockinged feet. No allowance was made on the weights for light clothing as worn, but men were asked to remove their jackets.

Total lung capacity and the subdivisions of lung volume were measured using modifications of the closed circuit techniques of Christie (1932) and McMichael (1939). In these measurements, too, some students had vital capacities (VC) which exceeded the limits of the spirometer, and in these cases VC was determined by adding together the inspiratory capacity (IC) and the expiratory reserve volume (ERV). We were able to show in other cases that VC was the same whether derived directly or from the addition of IC and ERV. Transfer factor (Dco) was also measured, using the single-breath technique of Ogilvie, Forster, Blakemore, and Morton (1957) and the improved procedures suggested by Jones and Meade (1960). Two observations were made with each subject, and the means were used in the analyses.

One student was so disturbed by the tests that it was impossible to complete the measurements of lung volume on him. Another, who complained of asthma, refused to have lung volume or transfer factor measurements made. In each of these cases, forced expiratory volume measurements were also unsatisfactory, and these two students were therefore excluded from all the tables relating to respiratory function, leaving 100 for whom complete measurements were available on the first occasion.

Measurements of airway resistance and thoracic gas volume, using a whole body plethysmograph, were made on a third visit, but the results of these measurements are to be reported in a separate paper.

The 'survivors' of the group, i.e., all those still pursuing their course at the College, were recalled in 1966-67, four years after the first series of interviews. The questions on the MRC form were asked again, and immediately afterwards measurements of airway resistance and thoracic gas volume were made in the body plethysmograph, followed by measurements of total lung capacity, subdivisions of lung volume, transfer factor and then the forced expiratory volumes and peak flow measurements, before and after administration of a bronchodilator. This order was used to minimize the risk of any one procedure disturbing the results from another, and the total time spent with each student was about one hour. A new spirometer with a larger bell, made to the design of Bernstein and Mendel (1953), was used for the expiratory volume measurements, and all forced vital capacities were recorded satisfactorily on this. The bells on the instruments used for lung volume and transfer factor measurements were also changed and re-calibrated, but there was no change in technique.

\section{RESULTS}

GENERAL CHARACTERISTICS Most of the students had entered the College straight from school, at the age of 18 to 19 (i.e., their dates of birth were mainly in 1943-44, during the war). They could not be regarded as a random sample of young people in that age range, for the proportion coming from 'professional' homes was far higher than in the general population. One-third of the students had fathers in the medical profession. Heights (as quoted in Table III) were above average, the mean for males being $4 \mathrm{~cm}$. greater than that found in young factory workers (Khosla and Lowe, 1968).

Smoking habits are shown in Table I: only $34 \%$ of the men and $10 \%$ of the women had smoked at all before coming to the College, and most of these were only light smokers. 
T A B L E I

DISTRIBUTION OF SMOKING HABITS

\begin{tabular}{|c|c|c|c|c|}
\hline & \multicolumn{4}{|c|}{ Actual Numbers in Each Category } \\
\hline & \multicolumn{2}{|c|}{ Male } & \multicolumn{2}{|c|}{ Female } \\
\hline & $1962-3$ & $1966-7$ & $1962-3$ & 1966-7 \\
\hline $\begin{array}{l}\text { Non-smokers } \\
\text { Ex-smokers } \\
\text { Cigarettes only } \\
<1 \text { per day } \\
1-4,,,,, \\
5-14,,,, \\
15-24 \text {,, ,' } \\
\text { Cigarettes plus pipe or cigars } \\
\text { Pipe and/or cigars }\end{array}$ & $\begin{array}{r}55 \\
3 \\
0 \\
0 \\
4 \\
10 \\
2 \\
2 \\
7\end{array}$ & $\begin{array}{r}39 \\
6 \\
1 \\
6 \\
4 \\
8 \\
2 \\
8\end{array}$ & $\begin{array}{r}17 \\
0 \\
0 \\
0 \\
1 \\
1 \\
0 \\
0\end{array}$ & $\begin{array}{r}13 \\
1 \\
1 \\
1 \\
2 \\
0 \\
0 \\
0\end{array}$ \\
\hline Total & 83 & 74 & 19 & 18 \\
\hline
\end{tabular}

\begin{tabular}{|c|c|c|}
\hline & \multicolumn{2}{|c|}{$\begin{array}{c}\text { Ave. Amount Smoked } \\
\text { per Week per Person } \\
\text { (Cigarettes or cigarette } \\
\text { equivalents) }\end{array}$} \\
\hline & Male & Female \\
\hline \multirow{2}{*}{$\begin{array}{l}\text { Students, } 1962-3 \text {, age } 19 \text {, all tobacco goods } \\
\text { Students, 1962-3, age } 19, \text { cigarettes } \\
\text { General population, } 1961 \text {, age } 16-19, \\
\text { cigarettes }\end{array}$} & $\begin{array}{l}17 \\
14\end{array}$ & $\begin{array}{l}11 \\
11\end{array}$ \\
\hline & 57 & 24 \\
\hline \multirow{2}{*}{$\begin{array}{l}\text { Students, } 1966-7 \text {, age } 23 \text {, all tobacco goods } \\
\text { Students, 1966-7, age } 23 \text {, cigarettes } \\
\text { General population, } 1965 \text {, age } 20-24 \text {, } \\
\text { cigarettes }\end{array}$} & $\begin{array}{l}28 \\
21\end{array}$ & $\begin{array}{l}9 \\
9\end{array}$ \\
\hline & 79 & 44 \\
\hline
\end{tabular}

Some of the students started to smoke, or increased the amount smoked, during the four-year interval before they were seen again, but others gave up smoking. The net result was an increase in the average amount smoked per male student, and a slight decrease in the case of females, but all the figures were well below those quoted for the general population (Todd, 1966).

RESPIRATORY SYMPTOMS As expected in this young and selectively fit group, few symptoms were reported. The proportions of positive answers to questions on symptoms are shown in Table II. The actual number of students who reported any change in severity of symptoms between the two visits are also shown.

Only two students reported a regular cough when first seen (one persisting for at least three months of the year, and the other not), but by the second visit several reported chronic cough and/ or phlegm: two of these had taken up smoking since the first visit, but otherwise there was nothing characteristic about the ones with increased symptoms.

More periods of acute illness with cough and phlegm were reported on the second occasion, and more chest illnesses sufficient to keep the students away from their studies. These questions related to the preceding three years, i.e., covering school
T A B L E I I

RESPIRATORY SYMPTOMS

\begin{tabular}{|c|c|c|c|c|c|}
\hline \multirow{2}{*}{$\begin{array}{l}\text { Ques- } \\
\text { tion } \\
\text { No. }\end{array}$} & \multirow{2}{*}{ Symptom } & \multicolumn{2}{|c|}{$\begin{array}{c}\text { Percentage } \\
\text { Positive }\end{array}$} & \multicolumn{2}{|c|}{ No. of Students } \\
\hline & & 1962-3 & 1966-7 & Better & Worse \\
\hline $\begin{array}{l}1-5 \\
6-10 \\
12 \\
14 \\
15 \\
17 \\
18-20 \\
21 \\
=\end{array}$ & $\begin{array}{l}\text { Cough (grade 1, 2) } \\
\text { Phlegm (grade 1,2) } \\
\text { Acute cough/phlegm } \\
\text { Breathlessness } \\
\quad \text { (grade } 2+\text { ) } \\
\text { Wheezing (grade 1,2) } \\
\text { Effect of weather } \\
\text { Nasal catarrh } \\
\text { Chest illness } \\
\text { Personal allergy } \\
\text { Family allergy }\end{array}$ & $\begin{array}{r}1 \\
0 \\
7 \\
\\
2 \\
30 \\
3 \\
15 \\
4 \\
27 \\
33\end{array}$ & $\begin{array}{r}5 \\
9 \\
20 \\
\\
2 \\
23 \\
2 \\
20 \\
11 \\
36 \\
34\end{array}$ & $\begin{array}{l}1 \\
0 \\
4 \\
1 \\
1 \\
9 \\
2 \\
5 \\
2 \\
0 \\
0\end{array}$ & $\begin{array}{r}5 \\
8 \\
17 \\
\\
0 \\
3 \\
1 \\
9 \\
9 \\
6 \\
0\end{array}$ \\
\hline No. of & $\begin{array}{ll}\text { students: } & \text { Total } \\
& \text { Male } \\
& \text { Female }\end{array}$ & $\begin{array}{r}102 \\
83 \\
19\end{array}$ & $\begin{array}{l}92 \\
74 \\
18\end{array}$ & & \\
\hline
\end{tabular}

In this table, cough and phlegm grades 1 and 2 relate to subjects reporting these symptoms, at any or all times of day, for as much as three months each year. Breathlessness grade 2 refers to shortness of breath when hurrying on the level or walking up a slight hil sounds. The figures for allergy include cases of eczema and food allergies as well as asthma and hay fever.

years on the first occasion and years at college on the second: the apparent increase in acute infections may have been due to a better 'recall' of such events once the students were more independent and were studying at a medical college. There was no evidence that these changes were related to smoking, nor were they confined to those who had previously lived outside the major conurbations. Only two students reported breathlessness $\rightleftharpoons$ on exertion, and one of them improved during the four-year interval, but a large proportion gave some history of wheezing (in most cases only occasional). This symptom was related to a history of respiratory allergy (asthma or hay-fever), which $\frac{\dot{0}}{3}$ was recorded separately, and whilst there was 3 . some increase between the two visits in the $\delta$ number reporting allergies (the question related $₹$ to the whole life-time experience), the proportion 을 currently reporting wheezing declined. The pro- $>$ portion reporting wheezing was a little higher among the smokers than among the non-smokers, N but the difference was not significant. It was also or higher $\left(\mathrm{P}<0.05, \chi^{2}\right.$ contingency test) among those $\tilde{O}$ who had previously lived in conurbations than among others. Nasal catarrh was also a relatively common symptom and there was a slight increase 0 from the first to the second visit in the propor- $\mathbb{D}$ tion reporting this. Any history of allergy in the $\stackrel{\infty}{+}$ family (mother and father) was noted, but this 0 was not closely linked with a personal history of allergy.

RESPIRATORY FUNCTION Results of the measurements of total lung capacity and its subdivisions, 
forced expiratory volume, peak expiratory flow and transfer factor made on 100 students in 1962-63 are shown in Table III. The values for each individual were also expressed as percentages of those predicted from the 'standard' tables of Cotes (1968), and the means of these percentages are also shown in Table III.

\section{T A B L E I I I}

RESPIRATORY FUNCTION MEASUREMENTS : MEAN VALUES FOR 81 MALES AND 19 FEMALES, 1962-3

\begin{tabular}{|c|c|c|c|c|c|c|}
\hline & \multicolumn{3}{|c|}{ Male } & \multicolumn{3}{|c|}{ Female } \\
\hline & Mean & SD & $\begin{array}{c}\% \\
\text { Predic- } \\
\text { ted }\end{array}$ & Mean & SD & $\begin{array}{c}\% \\
\text { Predic- } \\
\text { ted }\end{array}$ \\
\hline $\begin{array}{ll}\text { Age (yrs) } & \\
\quad 1 \text { Jan. 1963 } & \ldots \\
\text { Height (m.) } & \ldots \\
\text { Weight (kg.) } & \ldots \\
\text { TLC (litres) } & \ldots \\
\text { VC (litres) } & \ldots \\
\text { FRC (litres) } & \ldots \\
\text { RV (litres) } & \ldots \\
\text { RV/TLC \% } & \ldots \\
\text { FEV 0.75 (litres) } \\
\text { FEV 1.0 (litres) } \\
\text { PEF (litres/min) } \\
\text { Transfer factor } \\
\text { (ml./min./mm.Hg) }\end{array}$ & \begin{tabular}{|c|}
19.5 \\
1.79 \\
72.1 \\
6.91 \\
5.57 \\
3.31 \\
1.34 \\
19.3 \\
4.04 \\
4.53 \\
565 \\
38.6
\end{tabular} & $\begin{array}{l}1.6 \\
0.05 \\
7 \cdot 3 \\
0.81 \\
0.63 \\
0.59 \\
0.36 \\
4 \cdot 0 \\
0.48 \\
0.52 \\
61 \\
5.2\end{array}$ & $\begin{array}{r}\bar{Z} \\
\overline{9} \\
99 \\
105 \\
92 \\
78 \\
82 \\
103 \\
86 \\
107\end{array}$ & $\begin{array}{c}19 \cdot 0 \\
1 \cdot 67 \\
63 \cdot 2 \\
4.96 \\
3.90 \\
2 \cdot 32 \\
1.06 \\
20 \cdot 7 \\
2.92 \\
3 \cdot 27 \\
.444 \\
26 \cdot 7\end{array}$ & $\begin{array}{c}0.9 \\
0.05 \\
9.6 \\
0.82 \\
0.48 \\
0.67 \\
0.53 \\
7.1 \\
0.45 \\
0.49 \\
66 \\
4.90\end{array}$ & $\begin{array}{c}\bar{Z} \\
\overline{88} \\
106 \\
93 \\
65 \\
76 \\
150 \\
95 \\
106\end{array}$ \\
\hline
\end{tabular}

Heights are quoted without shoes, and weight with light clothes. Spirometric readings have been corrected to BTPS and transfer factor to STPD.

In general there was close agreement between the means of the observed and predicted values, but residual volumes (RV) were lower than those predicted from the tables: among the men, PEFs were also lower than expected. Predicted values for $\mathrm{FEV}_{1.0}$ and FVC were also computed using the regression equations of Ashford et al. (1968), obtained from their survey of coal miners. When our results for $\mathrm{FEV}_{1 \cdot 0}$ were expressed as percentages of these predicted values, the mean per cent predicted was $100 \%$ for the non-smokers and $106 \%$ for the smokers. Nearly all the students were within $\pm 20 \%$ of the predicted values for $\mathrm{FEV}_{1 \cdot 0}$ : one student just below this range was an asthmatic, but there was nothing unusual about two who were just above it. High values were not related to training for athletic activities.

Differences in lung function between the following sub-groups of the population were also examined: smokers and non-smokers, those with and without a history of respiratory allergy and those who had lived in conurbations before, or elsewhere. The mean values of PEF and $F V_{1.0}$ were just a little lower in those from conurbations than in others, but the only significant differences noted were higher values for transfer factor among non-smokers than among smokers, and among those with a history of respiratory allergy than among others.

Most students showed small increases in each of the measurements of forced expiratory volume and peak expiratory flow after the administration of isoprenaline, but some decreased a little. The greatest changes were in students reporting respiratory allergy, and on the first visit the mean increase in $\mathrm{FEV}_{1.0}$ in this group (3.8\%) was significantly greater than in those without such allergy $(3 \cdot 1 \%)$. Most of the measurements of lung function showed very little change between the first and the second visit (Table IV). In the case of FEV and PEF nearly all the students had results that were within $\pm 20 \%$ of their earlier readings, and the differences between means for the group of 91 students for whom complete data were available on both visits were small and not significant.

T A B L E I V

CHANGES IN RESPIRATORY FUNCTION, 1ST TO 2ND VISIT, AND CORRELATION BETWEEN VALUES FROM THE TWO VISITS, 91 MALES AND FEMALES

\begin{tabular}{|c|c|c|c|c|c|}
\hline & & & & $\begin{array}{c}\% \text { Change } \\
\text { 1st to } 2 \text { nd Visit }\end{array}$ & $\begin{array}{l}\text { Correlation } \\
\text { Coefficient }\end{array}$ \\
\hline $\begin{array}{l}\text { Height } \\
\text { Weight } \\
\text { TLC } \quad . \\
\text { VC } \quad . \\
\text { FRC } \quad . \\
\text { RV } \\
\text { RV/TLC } \% \\
\text { FEV } 0.75 \\
\text { FEV } \\
\text { PEF } \\
\text { Transfer factor }\end{array}$ & $\begin{array}{l}\cdots \\
\cdots \\
\cdots \\
\cdots \\
\cdots \\
\cdots \\
\cdots \\
\dot{o r}\end{array}$ & $\begin{array}{l}\cdots \\
\cdots \\
\cdots \\
\cdots \\
\cdots \\
\cdots \\
\cdots \\
\cdots\end{array}$ & $\begin{array}{l}\ldots \\
\cdots \\
\cdots \\
\cdots \\
\cdots \\
\cdots \\
\cdots \\
\cdots\end{array}$ & $\begin{array}{r}0 \\
2 \cdot 1 \\
2 \cdot 3 \\
3 \cdot 1 \\
3 \cdot 2 \\
-0 \cdot 9 \\
-3 \cdot 3 \\
3 \cdot 9 \\
3 \cdot 1 \\
2 \cdot 0 \\
-4 \cdot 8\end{array}$ & $\begin{array}{l}0.99 \\
0.90 \\
0.94 \\
0.96 \\
0.95 \\
0.66 \\
0.57 \\
0.94 \\
0.95 \\
0.90 \\
0.80\end{array}$ \\
\hline
\end{tabular}

There were greater changes in some of the static lung volume measurements, and in transfer factor, but again the differences between means were not significant. In some individuals there were minor differences in height as measured on the two occasions, but there was no evidence of growth and the difference in the mean heights was infinitesimal. The increase in mean weight was due mainly to an increase among men, for the women had in general lost weight.

The somewhat erratic changes in transfer factor and residual volumes are reflected in the lower correlation coefficients between measurements made on the first and second visits. Transfer factor is known to be lower after meals (Cotes, 1968), and since students came to us at various times of the day, some before and others after lunch, this variation could have increased the variance within and between visits. In subsequent experiments on other subjects (unpublished results) we have found variations of the order of 
$20 \%$ in transfer factor measured at different times during the day.

In contrast with other lung volume and forced expiratory volume measurements, residual volume was only poorly correlated with height, and some other factors appeared to be affecting the variation between students and between visits. Although RV was not correlated with weight within either the first or second visit results, it was negatively correlated with 'Quetelet's' index of adiposity (as defined by Billewicz, Kemsley, and Thomson, 1962). Changes in RV in individuals between the first and second visit were also negatively correlated with changes in weight or in the adiposity index. It seemed likely, therefore, that some aspects of body build, and of development between visits, were affecting residual volume. The relatively low values of $R V$ found in this series were balanced by high values of ERV: the results for men were $124 \%$ of those predicted from the data of Needham, Rogan, and McDonald (1954), and those for women were $133 \%$ of the predicted values.

Weight and adiposity did not appear to be important factors in determining the values of any of the other quantities measured in our series, and since age was virtually constant, it was possible to study the regression of each of these quantities on height alone, using equations of the type: Lung function $=a+b$ (height). The series was not large enough to warrant the use of standing height and sitting height as separate variables, and in Table $\mathrm{V}$ the coefficients are quoted for equations involving standing height alone.

T A B L E V

REGRESSION COEFFICIENTS FOR LUNG FUNCTION MEASUREMENTS ON STANDING HEIGHT (METRES).
MALES ONLY, FIRST VISIT

\begin{tabular}{|c|c|c|c|}
\hline & $\begin{array}{c}\text { Constant, } \\
a\end{array}$ & $\begin{array}{l}\text { Regression } \\
\text { Coefficient, } \\
\quad b\end{array}$ & $\begin{array}{c}\text { Correlation } \\
\text { Coefficient, } \\
r\end{array}$ \\
\hline $\begin{array}{l}\text { TLC (litres) } \\
\text { VC (litres) }\end{array}$ & $\begin{array}{l}-8.71(-8.49) \\
-6.66(-4.04) \\
-2.06(-3.11) \\
-6.52(-3.92) \\
-6.69(-2.03) \\
-84.2(0) \\
-32.8(-21.6)\end{array}$ & $\begin{array}{l}8 \cdot 74(8 \cdot 67) \\
6 \cdot 84(5 \cdot 20) \\
1.90(2 \cdot 70) \\
5 \cdot 51(5 \cdot 78) \\
6 \cdot 28(3.62) \\
363(365)\end{array}$ & $\begin{array}{l}0.59 \\
0.59 \\
0.29 \\
0.51 \\
0.65 \\
0.32 \\
\\
0.42\end{array}$ \\
\hline
\end{tabular}

Only males are considered in this table, and where possible comparisons have been made with other published figures. Cotes (1968) quotes a selection of equations published by various authors: the coefficients vary between authors, and in general our figures are close to at least one of the published sets. The only substantial departure is in the case of $\mathrm{FEV}_{1 \cdot 0}$ : our equation indicates a steeper slope than in other series, over the height range of our group. The regression analyses of $\frac{\bar{\sigma}}{\bar{N}}$ Ashford et al. (1968), based on their large study of coal miners, also give relatively steep slopes in $\stackrel{\mathbb{Q}}{2}$ the younger age ranges, and for a group such as ours (mean age 19.5 and mainly non-smokers) the simple regression on height, combining standing and sitting heights into one variable, is similar to that determined from our own results.

\section{DISCUSSION}

Although this investigation is intended to be the initial phase of a true 'cohort' study, the findings from the first examination are of interest on a 은 cross-sectional basis. The prevalence of bronchitic $\vec{z}$ symptoms (cough, phlegm and breathlessness) was extremely low, and no distinction could be made $\widehat{\widehat{S}}$ between smokers and non-smokers. In a study of senior students at Harvard (Peters and Ferris, 1967), some of whom had been heavy smokers for several years, a higher prevalence was found, and for some symptoms there were significant differences between smokers and non-smokers. One measurement of lung function that was lower in students who smoked than in others was transfer $\stackrel{\mathbb{Q}}{\varrho}$ factor. We cannot exclude the possibility that this $\overrightarrow{\vec{B}}$ was due to the smokers being a selected group in respect of some other relevant variable, but this finding warrants further investigation in a larger group which contains more smokers. Those reporting a history of respiratory allergy had a 음 higher transfer factor than others, but this did not account for the higher values in non-smokers. $\frac{0}{2}$ Wilson, Meador, Jay, and Higgins (1960) have reported differences in transfer factor between $\delta$ smokers and non-smokers, and it has also been reported (Ogilvie, 1968) that asthmatic patients 윽 have relatively high transfer factors. We did not find any close association between previous residential history and respiratory symptoms or lung function.

Our group was 'selected' in many ways, and $\tilde{O}$ was clearly made up of fit people with minimal స్ symptoms when first seen at age 19. Despite the fact that there were few changes in smoking habits among these students during their course, and $\frac{2}{\mathbb{D}}$ there were no heavy smokers, the four years' ? interval between the two examinations reported 0 here led to some increase in symptoms associated 0 with bronchitis, though the prevalence was still $\stackrel{\mathbb{\Omega}}{\Omega}$ too low to distinguish differences between $\mathbb{\mathbb { Q }}$ smokers and non-smokers. We have not, on a 'cohort' basis, seen any appreciable change in lung 
function in our group in the first four years of the study. This is as expected from the findings on coal miners (Ashford et al., 1968), among whom forced expiratory volume was still increasing below age 20 but began to decrease above that age. Our study covered the period from age 19 to 23, on the 'flat' part of the curve, where lung function appears to become stable at the adult level. Also the extent to which the students smoked was not sufficient to make any appreciable difference to their lung function.

There appears to be a need for further studies in which initial values of lung function in young adults can be established before smoking and occupational factors begin to exert their effects. The problems encountered in making all the required measurements on our sample on the first occasion were largely overcome on the second visit, and we consider now that it would be feasible to attempt a further study on a more representative sample of the population. Although our initial sample was too small to demonstrate significant differences in respiratory symptoms or function between sub-groups, there were some interesting trends, and with a larger sample it may be possible to detect effects of environmental factors in early life, which are of particular interest to us.

We plan to follow up this sample of medical students on a true cohort basis, at intervals of about five years, although it is already clear that emigration may be a hindrance.

We would like to record our appreciation of the large part played in this study by our colleagues in the Air Pollution Research Unit. Miss J. Addison,
Miss V. Roberts, and Miss D. Howard were responsible for making many of the measurements.

\section{REFERENCES}

Ashford, J. R., Brown, S., Morgan, D. C., and Rae, S. (1968), The pulmonary ventilatory function of coal miners in the United Kingdom. Amer. Rev. resp. Dis., 97, 810.

Bernstein, L., and Mendel, D. (1953). A spirometer which can be used at high respiratory rates. J. Physiol. (Lond.), 119, 3P.

Billewicz, W. Z., Kemsley, W. F. F., and Thomson, A. M. (1962). Indices of adiposity. Brit. J. prev. soc. Med., 16, 183.

Christie, R. V. (1932). The lung volume and its subdivisions 1. Methods of measurement. J. clin. Invest., 11, 1099.

Cotes, J. E. (1968). Lung Function: Assessment and Application in Medicine. 2nd ed. Blackwell, Oxford.

Douglas, J. W. B., and Waller, R. E. (1966). Air pollution and respiratory infection in children. Brit. J. prev. soc. Med., $20,1$.

Jones, R. S., and Meade, F. (1960). Pulmonary diffusing capacity. An improved single breath method. Lancet, 1, 94.

Khosla, T., and Lowe, C. R. (1968). Height and weight of British men. Lancet, 1, 742.

Lowe, C. R., Pelmear, P. L., Campbell, H., Hitchens, R. A. N. Khosla, T., and King, T. C. (1968). Bronchitis in two integrated steel works. I. Ventilatory capacity, age and physique of nonbronchitic men. Brit. J. prev. soc. Med., 22, 1.

McMichael, J. (1939). A rapid method of determining lung capacity. J. clin. Sci., 4, 167.

Medical Research Council (1962). Instructions for the Use of the Short Questionnaire on Respiratory Symptoms (1960), and additional duplicated notes dated 1961. Medical Research Council London. [Note: This has been superseded by the Questionnaire London. [Note: This has been superseded by the Questionnaire
on Respiratory Symptoms (1966) : forms and instructions distrion Respiratory Symptoms (1966) : forms and in
buted by W. J. Holman Ltd., Dawlish, Devon.]

Needham, C. D., Rogan, M. C., and McDonald, I. (1954). Normal standards for lung volumes, intra-pulmonary gas mixing and maximum breathing capacity. Thorax, 9,313 .

Ogilvie, C. M. (1968). Pulmonary function in asthma. Brit. med. J., $1,768$.

- Forster, R. E., Blakemore, W. S., and Morton, J. W. (1957). A standardized breath-holding technique for the clinical measurement of the diffusing capacity of the lung for carbon monoxide. J. clin. Invest., 36, 1.

Peters, J. M., and Ferris, B. G., Jr. (1967). Smoking, pulmonary function and respiratory symptoms in a college-age group. Amer. Rev. resp. Dis., 95, 774.

Todd, G. F. (1966). Statistics of Smoking in the United Kingdom. Research paper no. 1,4th ed. Tobacco Research Council, London.

Wilson, R. H., Meador, R. S., Jay, B. E., and Higgins, E. (1960). The pulmonary pathologic physiology of persons who smoke cigarettes. New Engl. J. Med., 262, 956.

Wright, B. M., and McKerrow, C. B. (1959). Maximum forced expiratory flow rate as a measure of ventilatory capacity. Brit. med. J., 2, 1041 . 